\title{
A meta-analysis of the effects of $\beta$-adrenergic blockers in chronic heart failure
}

\author{
XIAOJIAN ZHANG ${ }^{1}$, CHENGWU SHEN $^{1}$, SHUJUN ZHAI $^{1}$, YUKUN LIU $^{2}$, WEN-WEI YUE ${ }^{3}$ and LI HAN $^{3}$ \\ ${ }^{1}$ Shandong Provincial Hospital Affiliated to Shandong University, Ji'nan, Shandong 250021; ${ }^{2}$ Laiwu Health School, \\ Laiwu, Shandong 271100; ${ }^{3}$ The Fourth People's Hospital of Ji'nan, Ji'nan, Shandong 250021, P.R. China
}

Received March 21, 2016; Accepted July 20, 2016

DOI: $10.3892 /$ etm.2016.3657

\begin{abstract}
Adrenergic $\beta$-blockers are drugs that bind to, but do not activate $\beta$-adrenergic receptors. Instead they block the actions of $\beta$-adrenergic agonists and are used for the treatment of various diseases such as cardiac arrhythmias, angina pectoris, myocardial infarction, hypertension, headache, migraines, stress, anxiety, prostate cancer, and heart failure. Several meta-analysis studies have shown that $\beta$-blockers improve the heart function and reduce the risks of cardiovascular events, rate of mortality, and sudden death through chronic heart failure $(\mathrm{CHF})$ of patients. The present study identified results from recent meta-analyses of $\beta$-adrenergic blockers and their usefulness in $\mathrm{CHF}$. Databases including Medline/Embase/Cochrane Central Register of Controlled Trials (CENTRAL), and PubMed were searched for the periods May, 1985 to March, 2011 and June, 2013 to August, 2015, and a number of studies identified. Results of those studies showed that use of $\beta$-blockers was associated with decreased sudden cardiac death in patients with heart failure. However, contradictory results have also been reported. The present meta-analysis aimed to determine the efficacy of $\beta$-blockers on mortality and morbidity in patients with heart failure. The results showed that mortality was significantly reduced by $\beta$-blocker treatment prior to the surgery of heart failure patients. The results from the meta-analysis studies showed that $\beta$-blocker treatment in heart failure patients correlated with a significant decrease in long-term mortality, even in patients that meet one or more exclusion criteria of the MERIT-HF study. In summary, the findings of the current meta-analysis revealed beneficial effects different $\beta$-blockers have on patients with heart failure or related heart disease.
\end{abstract}

Correspondence to: Dr Wen-Wei Yue or Dr Li Han, The Fourth People's Hospital of Ji'nan, No. 50 Jianshe Road, Ji'nan, Shandong 250021, P.R. China

E-mail: gzd288@163.com

E-mail: fs1827@163.com

Key words: $\beta$-adrenergic, $\beta$-blockers, chronic heart failure

\section{Introduction}

$\beta$-blockers generally improve the symptoms and reduce the risk of cardiovascular events. However, there is no conclusive definition regarding the most sensitive endpoint for the efficacy of $\beta$-blockers in the treatment of chronic heart failure (CHF). A meta-analysis published in 1998 included 18 published double-blind, placebo-controlled, parallel-group trials of $\beta$-blockers in 3,023 patients with heart failure, which supported the therapeutic benefits of $\beta$-blockers treatment on left ventricular ejection fraction, New York Heart Association (NYHA) functional class, hospital stays and mortality rate (1). The $\beta$-blockers showed the most significant effects on ejection fraction and on the combined risk of mortality and hospital stays in patients with heart failure. The ejection fraction was increased by $\beta$-blockers by $29 \%(\mathrm{P}<10-9)$. Additionally, $\beta$-blockers significantly reduced the combined risk of mortality and hospital stays in patients with heart failure by $37 \%(\mathrm{P}<0.001)$. The two effects remained statistically significant when $<90 \%$ trials were excluded from the analysis, or when a number of trials with a neutral result were added to the analysis (1). By contrast, improvement on the NYHA functional class by $\beta$-blockers was of borderline significance $(\mathrm{P}=0.04)$, which became of no statistical significance when even one moderate-size study was added or removed from the analysis. In addition, $\beta$-blockade significantly reduced mortality by $32 \%(\mathrm{P}=0.003)$, although this effect was only moderately strong and varied depending on the type of $\beta$-blocker used, i.e., non-selective $\beta$-blockers were significantly more effective in reducing mortality risk than $\beta 1$-selective agents (49 vs. 18\%, $\mathrm{P}=0.049$ ) (1). By contrast, selective and non-selective $\beta$-blockers were not significantly different when their clinical efficacy was evaluated using other measures. Therapeutic benefits of $\beta$-blockers on ejection fraction and the combined risk of mortality and hospital stays in patients with heart failure were thus identified.

Due to their ability to prevent against adverse effects resulting from sympathetic stimulation on the failing heart (2), $\beta$-adrenergic blocking agents have been widely used for the treatment of heart failure, and provided therapeutic benefits to patients in a large number of clinical trials $(3,4)$. These clinical trials varied markedly in sample size and duration, baseline characteristics, and study objectives. In addition, the $\beta$-blockers used in these trials varied in selectivity for 
adrenergic receptors and effects on the peripheral blood circulation. The results from the meta-analysis studies on the $\beta$-blockers treatment for $\mathrm{CHF}$ were assessed.

\section{Materials and methods}

The literature regarding meta-analysis studies was searched from May, 1985 to March, 2011 and June, 2013 to August, 2015, in databases including Medline/Embase/Cochrane Central Register of Controlled Trials (CENTRAL), and PubMed. The results of various publications on metaanalyses were combined from published double-blind, placebo-controlled, parallel-group trials of $\beta$-blockers in thousands of patients with heart failure from a variety of investigators and research labs. The odds ratios (ORs) and 95\% confidence intervals (CIs) were presented from a number of meta-analysis studies of patients with heart failure.

Statistical analysis. Statistical analysis was conducted using the fixed-effect by (Mantel and Haenszel) and random-effect methods (6). The patients were regarded as a single unit of analysis to investigate the therapeutic benefits of $\beta$-blockers on SCD, CVD, and all-cause mortality. Similar results were obtained using either method, but only the random-effect results were reported. The efficacy was determined by odds ratios (ORs) with a 95\% confidence interval (CI). The heterogenic nature of the trials was evaluated using the $\chi^{2}$ test (6). The $\chi^{2}$ test values of 25,50 and $75 \%$ were defined as low, moderate, and high levels of heterogeneity, respectively (7). The results from the meta-analysis were documented only in the case of the $\chi^{2}$ value being $<75 \%$. The sensitivity analysis was conducted for each outcome measure to evaluate the contribution of each trial to the total estimate by removing single trials one at a time and performing the analysis based on the remaining trials. The statistical analysis was conducted in a two-tailed manner. $\mathrm{P}<0.05$ was defined as statistically significant. The data were processed utilizing RevMan software (version 5.3, Copenhagen: The Nordic Cochrane Centre, The Cochrane Collaboration, 2014)

\section{Results and Discussion}

Meta-analysis of $\beta$-blockers. In the meta-analysis by Lechat et al (1), 18 trials that included 3,023 patients with heart failure, with 1,305 treated with placebo and the remaining 1,718 patients with a $\beta$-blocker were reported. Of these patients, 1,513 patients had heart failure due to idiopathic dilated cardiopathy while 1,445 patients had heart failure due to ischemic heart disease (IHD). Most of the patients were taking diuretics, digitalis and an angiotensinconverting enzyme (ACE) inhibitor and exhibited NYHA class II or III symptoms. Only $\leq 5 \%$ patients had class IV symptoms, and class I patients were included in only two trials. The mortality rate for patients receiving placebo was $11.9 \%$ (156 deaths in 1,305) compared to $7.5 \%$ for patients receiving $\beta$-blocker (130 deaths in 1,718), indicating that the $\beta$-blocker significantly reduced the risk of death $[95 \% \mathrm{CI}$, $12-47 \%, P=0.003$ (Peto's method)]. When hospitalization was compared, 223 hospitalizations were reported from the placebo group (17.1\%) and 166 from the $\beta$-blocker group
(9.6\%), suggesting that the $\beta$-blocker significantly reduced the risk of hospitalization $(\mathrm{P}<0.001)$. We combined morbidity and mortality and the results showed that $25.4 \%$ patients in the placebo group died or were hospitalized while only 239 such events occurred in the $\beta$-blocker groups (16.0\%). This result showed that the $\beta$-blocker treatment was associated with a $37 \%$ reduction in risk (95\% CI, 24-49\%), $\mathrm{P}<0.001$.

By contrast, the patients treated with $\beta$-blocker were $32 \%$ more likely to show improvement in NYHA class $(\mathrm{P}=0.04)$ and $30 \%$ less likely to experience worsening of NYHA class $(\mathrm{P}=0.03)$. Patients in the placebo group presented with a mean unweighted value for left ventricular ejection fraction of $0.23 \pm 0.04$ compared with $0.31 \pm 0.04$ in the $\beta$-blocker groups, suggesting a significant increase in ejection fraction by $\beta$-blockers $(\mathrm{P}<10-9)$. Based on the assumption that the duration of treatment was the same as the mean follow-up (7 months), it was calculated that 38 patients required treatment to prevent 1 case of death, 24 patients to prevent 1 case of hospitalization for heart failure, and 15 patients to prevent 1 combined endpoint. The present findings also suggest that $\beta$-blockers probably improved survival and correlated with relatively fewer lethal events. However, the fact that selective and non-selective $\beta$-blockers showed different effects on mortality suggested that future studies are required before a conclusion on the ability of $\beta$-blockers to improve survival are created. In addition, novel information was obtained from a few ongoing trials of selective (CIBIS II and MERIT) and non-selective (BEST and COPERNICUS) $\beta$-blockers. A meta-analysis of randomized controlled trials on $\beta$-blockers in the prevention of sudden cardiac death (SCD) in patients with heart failure has been conducted by Al-Gobari et al (5).

In many studies, $\beta$-blockers have been shown to decrease SCD in HF patients, whereas other studies have shown mixed results. The results of several studies of large randomized control trials of $\beta$-blockers have been previously reported (3). The new findings have been summarized in a systematic review that currently presents available data on the use of $\beta$-blockers. A meta-analysis was also performed to analyze randomized controlled trials comparing the efficacy of $\beta$-blockers in the prevention of SCD in patients with heart failure (2). In a total of 30 trials, 24,779 patients were randomized to receive $\beta$-blocker or placebo/control. The study was performed following the preferred reporting items for systematic reviews and meta-analysis guidelines. The eligible studies presented an analysis on the incidence of SCD in patients with heart failure. Further inclusion criteria were: therapeutic regimen $>30$ days and follow-up time period of $>3$ months. Any studies that recruited patients $<8$ years, randomization to $\beta$-blocker versus an ACE (without placebo) and/or $\beta$-blocker in both arms were excluded from the analysis. The pre-defined markers comprised SCD, cardiovascular death (CVD), and all-cause mortality. In addition, these pre-defined markers were studied according to intention-to-treat. The analysis results suggested that the use of $\beta$-blockers was associated with significantly fewer cases of SCD, CVD and all-cause mortality. Therefore, according to data analysis, the number of patients required to receive $\beta$-blocker to avoid 1 case of SCD was 43 , the number to avoid 1 case of CVD was 26 and the number to avoid all-cause mortality over a 12 -month period was 21 . Treatment with $\beta$-blockers decreased the risk of SCD by $31 \%$, CVD by $29 \%$ 
Table I. Randomized trials of $\beta$-blockers for the prevention of sudden cardiac death.

\begin{tabular}{|c|c|c|c|c|c|c|c|}
\hline Authors (year) & $\begin{array}{c}\text { No. of } \\
\text { patients }\end{array}$ & $\begin{array}{l}\text { Name of } \\
\text { drug }\end{array}$ & Comparator & $\begin{array}{l}\text { Daily } \\
\text { maintenance } \\
\text { dose }\end{array}$ & Follow-up & $\begin{array}{c}\text { Jaded (reference) } \\
\text { patients of (months) } \\
\text { scoring (mg) }\end{array}$ & Refs. \\
\hline Anderson et al (1985) & 50 & Metoprolol & Control & 61 & 19 & 3 & (8) \\
\hline $\begin{array}{l}\text { Beta-Blocker Evaluation } \\
\text { of Survival Trial } \\
\text { Investigators (2001) }\end{array}$ & 2,708 & Bucindolol & Placebo & 152 & 24 & 5 & $(11)$ \\
\hline No authors listed (1997) & 415 & Carvedilol & Placebo & 12.5 & 19 & 4 & (12) \\
\hline Chadda (1986) & 3,837 & Propranolol & Placebo & $180 / 240$ & 25 & 5 & (13) \\
\hline Bristow et al (1994) & 139 & Bucindolol & Placebo & $12.5 / 50 / 200$ & 3 & 5 & (14) \\
\hline Bristow et al (1996) & 345 & Carvedilol & Placebo & $12.5 / 25 / 50$ & 6 & 5 & $(15)$ \\
\hline Dargie (2001) & 1,959 & Carvedilol & Placebo & 50 & 15.6 & 5 & (16) \\
\hline No authors listed (1999) & 2,647 & Bisoprolol & Placebo & 10 & 15 & 5 & $(17)$ \\
\hline No authors listed (1994) & 641 & Bisoprolol & Placebo & 5 & 23 & 5 & $(18)$ \\
\hline Witchitz et al (2000) & 124 & Celiprolol & Placebo & 100 & 12 & 5 & (19) \\
\hline Colucci et al (1996) & 366 & Carvedilol & Placebo & 100 & 15 & 5 & $(20)$ \\
\hline Packer et al (2002) & 2,289 & Carvedilol & Placebo & 50 & 10.4 & 5 & $(21)$ \\
\hline de Milliano et al (2002) & 59 & Metoprolol & Placebo & 150 & 6 & 5 & $(22)$ \\
\hline Conraads et al (2012) & 116 & Nebivelol & Placebo & $5 / 10$ & 6 & 5 & $(23)$ \\
\hline Engelmeir et al (1985) & 25 & Metoprolol & Placebo & 92 & 12 & 4 & $(24)$ \\
\hline Fisher et al (1994) & 50 & Metoprolol & Placebo & 87 & 6 & 5 & $(25)$ \\
\hline Hansteen et al (1982) & 560 & Propranolol & Placebo & 160 & 12 & 5 & $(26)$ \\
\hline Krum et al (1995) & 49 & Carvedilol & Placebo & 50 & 4 & 5 & $(27)$ \\
\hline Waagstein et al (1993) & 383 & Metoprolol & Placebo & $108 / 115$ & 18 & 3 & $(28)$ \\
\hline No authors listed (1999) & 3,991 & Metoprolol & Placebo & $159 / 170$ & 12 & 5 & $(29)$ \\
\hline Metra et al (1994) & 40 & Carvedilol & Placebo & 50 & 4 & 4 & $(30)$ \\
\hline Olsen et al (1995) & 60 & Carvedilol & Placebo & 81 & 4 & 5 & $(31)$ \\
\hline Packer et al (1996) & 1,094 & Carvedilol & Placebo & 60 & 6 & 5 & $(32)$ \\
\hline Pollock et al (1990) & 19 & Bucindolol & Placebo & 200 & 3 & 4 & (33) \\
\hline No authors listed (2000) & 426 & Metoprolol & Placebo & 156 & 6 & 5 & (34) \\
\hline Flather et al (2005) & 2,128 & Nebivelol & Placebo & 7.7 & 21 & 5 & $(35)$ \\
\hline Sturm et al (2000) & 100 & Atenolol & Placebo & 89 & 24 & 5 & $(36)$ \\
\hline Uhlir et al (1997) & 91 & Nebivelol & Placebo & $2.5 / 5$ & 3.5 & 5 & $(37)$ \\
\hline Wisenbaugh et al (1993) & 24 & Nebivelol & Placebo & 5 & 3 & 5 & (38) \\
\hline Woodley et al (1991) & 50 & Bucindolol & Placebo & 175 & 3 & 5 & (39) \\
\hline
\end{tabular}

and all-cause mortality by $33 \%$. These results confirmed the mortality benefits of $\beta$-blocker drugs, which should be recommended to all heart patients similar to those included in these trials. The features of trials and study quality are listed in Table I (5), and included 30 randomized controlled trials of $\beta$-blocker with a total of 24,779 cardiac patients.

After the Medline database and the Cochrane Library were searched, 441 studies were chosen to be reviewed according to the inclusion and exclusion criteria. Of these studies, 361 were excluded for the following causes: non-randomized study ( $\mathrm{n}=349)$, lack of placebo or inactive control group $(n=11)$, and enrollment of patients $<18$ years $(n=1)$. The full texts of the remaining 81 articles were obtained for further review. Based on the detailed review, another 51 trials were excluded due to the following reasons: absence of placebo or control $(n=9)$, duplicate report or substudy $(n=16)$, absence of a $\beta$-blocker arm $(n=10)$, outcome of no interest $(n=15)$ and use of $\beta$-blockers in both arms $(n=1)$. For features of studies (Table I), the mean follow-up time was 11.51 months ( 0.96 year) and all but one trial was placebo-controlled (8). The Jadad scoring was utilized (9). The trials were scored between 3 and 5, suggesting high quality. The studies were analyzed following the intention-to treat paradigm. The risk of SCD was most prominent in heart failure patients who had absolute risk of SCD in 1 year between 4 and 13\% (10).

A randomized trial was conducted to determine the effect of nebivolol on mortality and cardiovascular hospital admission in elderly patients with heart failure [Al-Gobari et al (5)]. For the efficacy of $\beta$-blockers, 3,764 cases of death were reported in the 24,779 patients included in the present analysis, comprising 1,597 SCDs. The SCD incidence was $5.27 \%$ $(n=673 / 12,768)$ in the $\beta$-blocker group relative to $7.69 \%$ $(n=924 / 12,011)$ in the placebo/control group $(P<0.00001)$. The cardiovascular mortality rate was $10.84 \%(n=1,236 / 11,398)$ 
in the $\beta$-blockers group and $14.86 \%(n=1,585 / 10,666)$ in the placebo/control group $(\mathrm{P}<0.00001)$. The all-cause mortality rate was $12.82 \%(\mathrm{n}=1,626 / 12,678)$ in the $\beta$-blockers group and $17.80 \%(\mathrm{n}=2,138 / 12,011)$ in the placebo/control group $(\mathrm{P}<0.00001)(5)$. According to the present analysis, the number of patients required to receive $\beta$-blocker to avoid 1 case of SCD was 43 , the number to avoid 1 case of CVD was 26 and the number to avoid all-cause mortality in a year was 21 . The forest plot comparison in SCD and all-cause mortality was performed between the $\beta$-blockers and placebo groups. The $\chi^{2}$ value was relatively low in SCD, CVD, and all-cause mortality $(0,20$ and $43 \%$, respectively). In this meta-analysis of 24,779 randomized patients, the $\beta$-blockers were effective in preventing SCD, CVD, and all-cause mortality. A majority of patients with severe congestive heart failure combined with ventricular arrhythmias, including non-sustained ventricular tachycardia (4). As anti-arrhythmic agents, $\beta$-blockers treatment is associated with reduced morbidity and mortality in patients with $\mathrm{CHF}$, and a markedly decreased risk of SCD. However, results from the present meta-analysis revealed a $32 \%$ decrease in SCD risk. As mentioned previously, the absolute risk of SCD within 1 year in patients with heart failure was $4-13 \%$ (10). In the present study, the 1-year absolute risk of SCD in the $\beta$-blocker and placebo/control groups was 5.5 and $8.10 \%$, respectively. The mortality rates increased in the higher (NYHA) class, but the percentage of patients succumbing to heart failure (rather than from progressive pump failure) was highest in those with less severe HF (NYHA class II or III) (MERIT-HF) (29). It is well known that $\beta$-blockers decrease overall and cardiovascular mortality in heart failure patients. A meta-analysis was performed to analyze their effect on sudden death, their efficacy, and whether there was any difference between vasodilating and non-vasodilating agents (40). Randomized, clinical trials were reviewed to evaluate a $\beta$-blocker without intrinsic sympatho-mimetic activity. The trials comprised a control group treated with a placebo or standard treatment, and mortality was appreciated on an intention-to-treat basis, and documented for $\geq 8$ weeks. In total, 21 trials with 5,849 patients $(3,130$ receiving $\beta$-blockers) were reviewed in the meta-analysis. The median length of treatment was 6 months. The majority of patients had mild or moderate heart failure and were treated with angiotensin-converting enzyme inhibitors, diuretics, and digitalis. The $\beta$-blockers significantly reduced overall mortality, cardiovascular mortality, and mortality due to pump failure and sudden death by $34-39 \%$. The decrease in overall mortality in patients with IHD (30\%) was no different from that among patients with non-IHD $(26 \%)(\mathrm{P}=0.08)$. The reduction in overall mortality was greater with vasodilating than with non-vasodilating agents (45 vs. $27 \% ; \mathrm{P}=.007)$, particularly in patients without IHD (62\%), compared with those with IHD (22\%; $\mathrm{P}=0.03)$ (40). The vasodilating $\beta$-blockers showed a greater effect on overall mortality than the non-vasodilating agents, particularly in patients with non-IHD. $\beta$-blockers generically available are subclassified and based on selective aspects of their action and include: acebutolol, bisoprolol, metoprolol, nadolol, propranolol, and timolol. The safety and effects of the $\beta$-blocker, nadolol, have been suggested in mild asthma by an open-label pilot study (41). $\beta$-blockers are currently applied with care in asthma patients because their acute administration may be associated with worsening broncho-spasm. However, their effects and safety are yet to be adequately evaluated. The use of $\beta$-blockers in congestive heart failure is successful, despite previously recorded acute detrimental effects (7). However $\beta$-blockers have been shown to reduce mortality with their chronic use. Certain $\beta$-blockers are safe and useful in chronic asthma therapy. In such cases, open-label, pilot studies, were conducted to determine the safety and effects of escalating doses of the $\beta$-blocker, nadolol, administered $>9$ weeks to 10 subjects with mild asthma. The dose escalation was performed on a weekly basis based on pre-determined safety lung function, asthma control, and hemodynamic parameters. The safety and effects of $\beta$-blockers on airway hyper-responsiveness, and indices of respiratory function have been described (6). Nadolol was effective in the cases of asthma. In $80 \%$ of tested patients, 9 weeks of treatment with nadolol resulted in a significant increase in PC20 in a dose-dependent manner, which reached 2.1-doubling doses at $40 \mathrm{mg}(\mathrm{P}<0.0042)$. In addition, a dose-independent $5 \%$ reduction in mean FEV1 was found over the study period $(\mathrm{P}<0.01)$. It was shown that in most patients with mild asthma, the dose-escalating administration of the $\beta$-blocker, nadolol, was well-tolerated and provided therapeutic benefits on airway hyper-responsiveness. These results suggest more testing of the drugs in large-scale studies.

Recently, Larochelle et al described the role of $\beta$-blockers in hypertension in a meta-analysis of studies spanning over several years (42). The $\beta$-blockers are among the most commonly used drugs in the treatment of hypertension. After 45 years of studies their initial indication for hypertension has been questioned based on evidence from the meta-analyses of clinical trials. The $\beta$-blocker class consists of various agents with many pharmacokinetic and pharmacodynamic properties including lipo- and hydrophilicity, duration of action, intrinsic sympathomimetic activity, vasodilation, and metabolism linked to genetic polymorphisms (32). $\beta$-blockers are also used for cardiovascular conditions such as angina, pain in heart, rate control of atrial fibrillation, CHF, and after myocardial infarction (MI), and other indications such as migraine and essential tremor. Over 17 large-scale trials influencing the recommendations on the use of $\beta$-blockers in the treatment of hypertension are available (37). $\beta$-blockers have been used as a first-line treatment option for patients $<60$ years of age, and are based on evidence from these large trials, which were supported by two of the meta-analyses. Matowa studied the use of $\beta$-blockers in patients of cardiac failure (43). A retrospective observational study was conducted by reviewing medical records (38). A total of 385 cardiac failure cases was included. The medical records of hospitalised patients for cardiac failure at the study center were abstracted. The results showed that $36(9.4 \%)$ patients were prescribed with $\beta$-blockers and 7 patients had their $\beta$-blocker substituted for another. Atenolol, propranolol and carvedilol were prescribed to 30 (7.8\%), 7 (1.8\%), and $6(1.6 \%)$ patients, respectively. Metoprolol and bisoprolol were not administered at all. More female (57.9\%) than male (42.1\%) subjects were included. The mean age was 41.9 (standard deviation, 24.0). The prevalence of hospital stay due to cardiac failure was $1.54 \%$. It was concluded that the use of $\beta$-blocker was not common. Therefore, this evidence-based treatment regimen for managing cardiac failure in patients 
from Zimbabwe, Africa, should be stressed. In a recent study, Bangalore et al analyzed the clinical outcomes of $\beta$-blockers for MI (44). Randomized trials including $\geq 100$ subjects were mined from Medline/Embase/CENTRAL to assess the role of $\beta$-blockers in MI. All-cause mortality was defined as the primary outcome. The analysis was conducted by stratifying studies into reperfusion-era or pre-reperfusion-era trials. The results were obtained from 60 studies comprising 102,003 patients who met the inclusion criteria. In the acute MI studies, a significant interaction (Pinteraction, 0.02) was noted. $\beta$-blockers reduced mortality in the pre-reperfusion era [incident rate ratio (IRR), 0.86; 95\% CI: 0.79-0.94] but not in the reperfusion era (IRR, 0.98; 95\% CI: 0.92-1.05). In the pre-reperfusion era (IRR, 0.72; 95\% CI: 0.62-0.83) [number needed to treat to benefit (NNTB)], $\beta$-blockers reduced cardiovascular mortality (IRR, 0.87; 95\% CI: 0.78-0.98), MI (IRR, 0.78; 95\% CI: 0.62-0.97), and angina (IRR, 0.88; 95\% CI: 0.82-0.95), with no difference for other outcomes. In the reperfusion era, $\beta$-blockers reduced MI $(\mathrm{NNTB}=209)$ and angina (IRR, 0.80; 95\% CI: 0.65-0.98) $(\mathrm{NNTB}=26)$ at the expense of increase in heart failure (IRR, 1.10 ; 95\% CI: $1.05-1.16$ ) [number needed to treat to harm $(\mathrm{NNTH})=79]$, cardiogenic shock (IRR, 1.29; 95\% CI: 1.18-1.41) (NNTH=90), and drug discontinuation (IRR, 1.64; 95\% CI: 1.55-1.73), with no benefit for other outcomes. The benefits for recurrent MI and angina in the reperfusion era appeared to be short term (30 days). It was concluded that in the current regimen of treatment of MI, $\beta$-blockers do not provide clinical benefits on mortality but prevent recurrent MI and angina (short-term) with increase in heart failure, cardiogenic shock, and discontinuation of drug.

A recent meta-analysis was performed on $\beta$-blockers and their role in heart failure with preserved ejection fraction (HFpEF) (45). $\beta$-blockers are well known as drugs used for the care of heart failure; however, their role in HFpEF is not known. Thus, a meta-analysis was performed to evaluate the efficacy of $\beta$-blockers on mortality and morbidity in HFpEF patients. A systematic mining in PubMed, Embase, Scopus and Cochrane databases was conducted to locate the relevant trials on $\beta$-blockers and $\mathrm{HFpEF}$. A random-effects model was performed to evaluate the effect of $\beta$-blockers on all-cause mortality and hospitalization due to HF. A total of 27,099 patients from 15 observational studies and two randomized control trials were included in the analysis. The $\beta$-blocker treatment significantly correlated with lower all-cause mortality. However, no change in HF hospitalization was found. In the two RCTs, $\beta$-blocker treatment did not result in signifciantly lower all-cause mortality or HF hospitalization $(\mathrm{P}>0.05)$. These results were consistent with geographic region (USA versus rest of world) and ejection fraction subgroups. The subgroup analysis revealed that the beneficial survival effect of $\beta$-blocker was limited to studies with subjects of mean age $<75$ years. The observational studies showed a significant benefit from the use of $\beta$-blockers for all-cause mortality, but not for HF hospitalization. The $\beta$-blockers in the two RCTs were not associated with a significant reduction in all-cause mortality or HF hospitalization, but the two trials were not adequately powered and had high loss to follow-up rates.

The benefit of $\beta$-blockers on prostate cancer mortality has been analyzed in a meta-analysis study of 16,825 patients (46).
The results suggested that $\beta$-blocker treatment correlated with decreased mortality in patients with prostate cancer. Data mining was performed from Medline (from 1 January 1966) and Embase (from 1 January 1974), through 10 September 2014, and the reference lists of pertinent articles were also located. The investigators independently screened and reviewed the eligibility of each study. The primary outcomes were defined as prostate cancer-specific mortality and all-cause mortality. The meta-analysis was conducted on the base of 4 studies including 16,825 patients. The results revealed that $\beta$-blocker treatment correlated with decreased prostate cancer-specific mortality without any heterogeneity between studies $(\mathrm{Q}=3.59$, $\left.\mathrm{I}^{2}=16.5 \%, \mathrm{P}=0.309\right)$. No correlation with all-cause mortality (hazard ratio $=0.97,95 \% \mathrm{CI}: 0.90-1.04$ ) was found. There was no significant heterogeneity between the 4 studies $(\mathrm{Q}=2.48$, $\left.\mathrm{I}^{2}=0.0 \%, \mathrm{P}=0.480\right)$. The analysis indicated that $\beta$-blocker use was associated with reduced cancer-specific mortality among prostate cancer patients taking $\beta$-blocker drugs. Use of $\beta$-blockers improves and protects the condition of heart patients from heart failure, hypertension, cardiac arrhythmias, angina pectoris (pain in heart), glaucoma of eyes, headache and migraines, stress and anxiety as well as prostate cancer (42). The meta-analysis studies also indicated that $\beta$-blockers preserved ejection fraction in heart failure patients. Andrews et al conducted a meta-analysis to determine the efficacy of digoxin, verapamil, and $\beta$-adrenoceptor blockers as prophylaxis against supraventricular arrhythmias (SVAs) after coronary artery bypass graft surgery (CABG) (47). Randomized control trials were performed and 24 of 69 identified studies were included in the final analysis. The OR of developing SVAs after CABG in the treatment versus control groups was calculated. The pooled mean ventricular rate during SVA in patients who developed arrhythmia was also calculated. The digoxin and verapamil did not reduce the likelihood of SVAs after CABG (digoxin: OR, 0.97, 95\% CI: 0.62-1.49; verapamil: OR, 0.91, 95\% CI: 0.57-1.46). The likelihood of developing SVA in patients treated with $\beta$-blockers was markedly decreased compared with the controls (OR, 0.28; 95\% CI: 0.21-0.36). The pooled ventricular rate when SVAs occurred was significantly decreased in each of the treatment groups. The prophylactic $\beta$-adrenoceptor blockers showed a protective effect against the development of SVAs in a selected population of patients undergoing CABG. However, no such beneficial effect was observed for digoxin or verapamil. The ventricular rate was reduced with all 3 agents in patients who developed the arrhythmia, although the ventricular rate reduction was not optimal clinically.

Recent advances in adrenergic $\beta$-blockers and CHF. To evaluate the efficacy of $\beta$-blockers in patients with heart failure and impaired ejection fraction, a network meta-analysis was performed (48). Data were mined from CINAHL (1982-2011), CENTRAL (1985-2011), Embase (1980-2011), Medline/PubMed (1966-2011), and Web of Science (1965-2011). Randomized trials that compared $\beta$-blockers with other $\beta$-blockers or other treatments were included. Data extraction was performed and the cause of death at the longest available follow-up was defined as the primary endpoint. The data were analyzed with ORs and Bayesian random effect $95 \%$ credible intervals, with independent extraction by 
observers. A total of 21 trials were included and $\beta$-blockers including atenolol, bisoprolol, bucindolol, carvedilol, metoprolol, and nebivolol, were used. When compared with placebo or standard treatment after a median of 12 months, $\beta$-blockers showed significant beneficial effects (OR, 0.69 , 95\% CI: 0.56-0.80). However, when the different $\beta$-blockers were compared head-to-head for the risk of death, SCD, death due to pump failure, or drug discontinuation, no significant difference was revealed. Improvements in left ventricular ejection fraction were also similar irrespective of the individual drug studied. The beneficial effects of $\beta$-blockers in patients with heart failure and impaired ejection fraction was mainly because of a class effect, as no statistics from currently available trials evidenced the advantage of any single agent over other treatments. Ma et al conducted a meta-analysis on the correlation between $\beta 1$-adrenergic receptor gene Arg389Gly polymorphism and risk of heart failure in humans (49). The studies were mined from the PubMed, Embase, and China National Knowledge Infrastructure databases and two reviewers independently evaluated the studies. The 6 case-control studies with a total of 1,736 participants were included in the meta-analysis, including 882 cases with heart failure and 854 controls. The results showed no association between Arg389Gly polymorphism and heart failure. No publication bias was identified (all $\mathrm{P}>0.05$ ).

The $\beta 1$-adrenergic receptor gene Arg389Gly polymorphism may not be associated with heart failure risk. Large-scale and well-designed studies are required to support these results. In a recent meta-analysis the role of $\beta$-adrenergic blockers in reducing perioperative cardiac risk in patients experiencing vascular surgery was investigated (50). This class of drugs may reduce the risk of perioperative cardiac complications in individuals experiencing major non-cardiac vascular surgery. The Cochrane Peripheral Vascular Diseases Group Trials Search Co-ordinator searched the Specialised Register (January 2014) and the CENTRAL (issue 12, 2013). The databases were mined and reference lists were reviewed for relevant studies. The study included prospective, randomized controlled trials of perioperative $\beta$-blockers of subjects $>18$ years experiencing non-cardiac vascular surgery. The two review authors independently carried out study identification and data extraction. The meta-analysis was carried out with a fixed-effect model with ORs and $95 \%$ CIs. The results from two double-blind, randomized controlled trials comparing perioperative effects of $\beta$-blockers (metoprolol) with placebo, on cardiovascular outcomes in subjects experiencing major non-cardiac vascular surgery were analyzed. A total of 599 subjects were included to be treated with $\beta$-blockers (301 subjects) or placebo (298 subjects). The outcomes were revealed only in a single study and neither of the studies reported on vascular patency/graft occlusion, which decreases the quality of evidence to moderate. There was no evidence to indicate that perioperative $\beta$-adrenergic blockade reduced all-cause mortality, cardiovascular mortality, non-fatal MI, arrhythmia, heart failure, stroke, composite cardiovascular events or re-hospitalisation at 30 days. However, there was strong evidence that $\beta$-adrenergic blockers increased the odds of intra-operative bradycardia (OR, 4.97, 95\% CI: 3.22-7.65; $\mathrm{P}<0.00001)$ and intra-operative hypotension $(\mathrm{OR}$,
1.84, 95\% CI: 1.31-2.59; $\mathrm{P}=0.0005)$. The meta-analysis did not strongly support that perioperative $\beta$-blockers improve postoperative cardiac morbidity and mortality in subjects experiencing major non-cardiac vascular surgery. However, $\beta$-blockers provided some therapeutic benefits in patients with heart failure and reduced ejection fraction according to the recent network of meta-analysis.

In conclusion, results of the meta-analysis studies have shown a marked decreased in the incidence of overall mortality, cardiovascular mortality, and sudden death by $34-39 \%$. $\beta$-blockers reduced mortality in patients with IHD by $30 \%$, which was not significantly different compared to non-IHD patients $(26 \%)(\mathrm{P}=0.08)$. The reduction in mortality was greater with vasodilating than with non-vasodilating agents ( 45 vs. $27 \%$; $\mathrm{P}=0.007$ ), particularly in patients without IHD (62\%), compared with those with IHD (22\%; P=0.03) (40). The $\beta$-blockers with vasodilating effects demonstrated a better efficacy on reducing mortality than the non-vasodilating agents, especially in non-IHD patients. In a meta-analysis study, the results did not support that perioperative treatment with $\beta$-blockers correlated with decreased postoperative cardiac morbidity and mortality in individuals experiencing major non-cardiac vascular surgery. The effects of $\beta$-blockers on heart failure patients with impaired ejection fraction was primarily because of a class effect, since no statistics from present studies supported the advantage of any single agent over other agents.

In summary, the findings of the meta-analyses have shown that $\beta$-blockers preserved ejection fraction in heart failure patients. The $\beta$-blockers reduced MI, angina, heart failure, and cardiogenic shock. The effects for recurrent MI and angina in the reperfusion era cannot last for long (only 30 days). The use of $\beta$-blockers is therefore useful in controling heart failure.

\section{References}

1. Lechat P, Packer M, Chalon S, Cucherat M, Arab T and Boissel JP: Clinical effects of beta-adrenergic blockade in chronic heart failure: a meta-analysis of double-blind, placebo-controlled, randomized trials. Circulation 98: 1184-1191, 1998.

2. Packer M: The neurohormonal hypothesis: A theory to explain the mechanism of disease progression in heart failure. J Am Coll Cardiol 20: 248-254, 1992.

3. Doughty RN, Rodgers A, Sharpe N and MacMahon S: Effects of beta-blocker therapy on mortality in patients with heart failure: A systematic overview of randomized controlled trials. Eur Heart J 18: 560-565, 1997.

4. Heidenreich PA, Lee TT and Massie BM: Effect of beta-blockade on mortality in patients with heart failure: a meta-analysis of randomized clinical trials. J Am Coll Cardiol 30: 27-34, 1997.

5. Al-Gobari M, El Khatib C, Pillon F and Gueyffier F: $\beta$-Blockers for the prevention of sudden cardiac death in heart failure patients: a meta-analysis of randomized controlled trials. BMC Cardiovasc Disord 13: 52, 2013.

6. DerSimonian R and Laird N: Meta-analysis in clinical trials. Control Clin Trials 7: 177-188, 1986.

7. Higgins JPT, Thompson SG, Deeks JJ and Altman DG: Measuring inconsistency in meta-analyses. BMJ 327: 557-560, 2003.

8. Anderson JL, Lutz JR, Gilbert EM, Sorensen SG, Yanowitz FG, Menlove RL and Bartholomew M: A randomized trial of low-dose beta-blockade therapy for idiopathic dilated cardiomyopathy. Am J Cardiol 55: 471-475, 1985.

9. Jadad AR, Moore RA, Carroll D, Jenkinson C, Reynolds DJ, Gavaghan DJ and McQuay HJ: Assessing the quality of reports of randomized clinical trials: Is blinding necessary? Control Clin Trials 17: 1-12, 1996. 
10. Piccini JP, Berger JS and O'Connor CM: Amiodarone for the prevention of sudden cardiac death: A meta-analysis of randomized controlled trials. Eur Heart J 30: 1245-1253, 2009 .

11. Beta-Blocker Evaluation of Survival Trial Investigators: A trial of the beta-blocker bucindolol in patients with advanced chronic heart failure. N Engl J Med 344: 1659-1667, 2001.

12. No authors listed: Randomised, placebo-controlled trial of carvedilol in patients with congestive heart failure due to ischaemic heart disease. Australia/New Zealand Heart Failure Research Collaborative Group. Lancet 349: 375-380, 1997.

13. Chadda K, Goldstein S, Byington R and Curb JD: Effect of propranolol after acute myocardial infarction in patients with congestive heart failure. Circulation 73: 503-510, 1986.

14. Bristow MR, O'Connell JB, Gilbert EM, French WJ, Leatherman G, Kantrowitz NE, Orie J, Smucker ML, Marshall G and Kelly P; Bucindolol Investigators: Dose-response of chronic beta-blocker treatment in heart failure from either idiopathic dilated or ischemic cardiomyopathy. Bucindolol Investigators. Circulation 89: 1632-1642, 1994.

15. Bristow MR, Gilbert EM, Abraham WT, Adams KF, Fowler MB, Hershberger RE, Kubo SH, Narahara KA, Ingersoll H, Krueger S, et al: Carvedilol produces dose-related improvements in left ventricular function and survival in subjects with chronic heart failure. MOCHA Investigators. Circulation 94: 2807-2816, 1996.

16. Dargie HJ: Effect of carvedilol on outcome after myocardial infarction in patients with left-ventricular dysfunction: the CAPRICORN randomised trial. Lancet 357: 1385-1390, 2001.

17. No authors listed: The Cardiac Insufficiency Bisoprolol Study II (CIBIS-II): A randomized trial. Lancet 353: 9-13, 1999.

18. No authors listed: A randomized trial of beta-blockade in heart failure. The Cardiac Insufficiency Bisoprolol Study (CIBIS). CIBIS Investigators and Committees. Circulation 90: 1765-1773, 1994.

19. Witchitz S, Cohen-Solal A, Dartois N, Weisslinger N, Juste K and Darmon JY: Treatment of heart failure with celiprolol, a cardioselective beta blocker with beta-2 agonist vasodilatory properties. The CELICARD Group. Am J Cardiol 85: 1467-1471, 2000.

20. Colucci WS, Packer M, Bristow MR, Gilbert EM, Cohn JN, Fowler MB, Krueger SK, Hershberger R, Uretsky BF, Bowers JA, et al: Carvedilol inhibits clinical progression in patients with mild symptoms of heart failure. US Carvedilol Heart Failure Study Group. Circulation 94: 2800-2806, 1996.

21. Packer M, Fowler MB, Roecker EB, Coats AJS, Katus HA, Krum H, Mohacsi P, Rouleau JL, Tendera M, Staiger C, et al; Carvedilol Prospective Randomized Cumulative Survival (COPERNICUS) Study Group: Effect of carvedilol on the morbidity of patients with severe chronic heart failure: Results of the carvedilol prospective randomized cumulative survival (COPERNICUS) study. Circulation 106: 2194-2199, 2002 .

22. de Milliano PA, de Groot AC, Tijssen JG, van Eck-Smit BL, Van Zwieten PA and Lie KI: Beneficial effects of metoprolol on myocardial sympathetic function: Evidence from a randomized, placebo-controlled study in patients with congestive heart failure. Am Heart J 144: E3, 2002.

23. Conraads VM, Metra M, Kamp O, De Keulenaer GW, Pieske B, Zamorano J, Vardas PE, Böhm M and Dei Cas L: Effects of the long-term administration of nebivolol on the clinical symptoms, exercise capacity, and left ventricular function of patients with diastolic dysfunction: results of the ELANDD study. Eur J Heart Fail 14: 219-225, 2012.

24. Engelmeier RS, O'Connell JB, Walsh R, Rad N, Scanlon PJ and Gunnar RM: Improvement in symptoms and exercise tolerance by metoprolol in patients with dilated cardiomyopathy: A double-blind, randomized, placebo-controlled trial. Circulation 72: 536-546, 1985

25. Fisher ML, Gottlieb SS, Plotnick GD, Greenberg NL, Patten RD, Bennett SK and Hamilton BP: Beneficial effects of metoprolol in heart failure associated with coronary artery disease: A randomized trial. J Am Coll Cardiol 23: 943-950, 1994

26. Hansteen V, Møinichen E, Lorentsen E, Andersen A, Strøm O, Søiland K, Dyrbekk D, Refsum AM, Tromsdal A, Knudsen $\mathrm{K}$, et al: One year's treatment with propranolol after myocardial infarction: Preliminary report of Norwegian multicentre trial. Br Med J (Clin Res Ed) 284: 155-160, 1982
27. Krum H, Sackner-Bernstein JD, Goldsmith RL, Kukin ML, Schwartz B, Penn J, Medina N, Yushak M, Horn E, Katz SD, et al: Double-blind, placebo-controlled study of the long-term efficacy of carvedilol in patients with severe chronic heart failure. Circulation 92: 1499-1506, 1995.

28. Waagstein F, Bristow MR, Swedberg K, Camerini F, Fowler MB, Silver MA, Gilbert EM, Johnson MR, Goss FG and Hjalmarson A: Beneficial effects of metoprolol in idiopathic dilated cardiomyopathy. Metoprolol in Dilated Cardiomyopathy (MDC) Trial Study Group. Lancet 342: 1441-1446, 1993.

29. No authors listed: Effect of metoprolol CR/XL in chronic heart failure: Metoprolol CR/XL Randomised Intervention Trial in Congestive Heart Failure (MERIT-HF). Lancet 353: 2001-2007, 1999.

30. Metra M, Nardi M, Giubbini R and Dei Cas L: Effects of shortand long-term carvedilol administration on rest and exercise hemodynamic variables, exercise capacity and clinical conditions in patients with idiopathic dilated cardiomyopathy. J Am Coll Cardiol 24: 1678-1687, 1994.

31. Olsen SL, Gilbert EM, Renlund DG, Taylor DO, Yanowitz FD and Bristow MR: Carvedilol improves left ventricular function and symptoms in chronic heart failure: A double-blind randomized study. J Am Coll Cardiol 25: 1225-1231, 1995.

32. Packer M, Bristow MR, Cohn JN, Colucci WS, Fowler MB, Gilbert EM and Shusterman NH: The effect of carvedilol on morbidity and mortality in patients with chronic heart failure. U.S. Carve-dilol Heart Failure Study Group. N Engl J Med 334: 1349-1355, 1996

33. Pollock SG, Lystash J, Tedesco C, Craddock G and Smucker ML: Usefulness of bucindolol in congestive heart failure. Am J Cardiol 66: 603-607, 1990.

34. No authors listed: Effects of metoprolol CR in patients with ischemic and dilated cardiomyopathy: the randomized evaluation of strategies of left ventricular dysfunction pilot study. Circulation 101: 378-384, 2000.

35. Flather MD, Shibata MC, Coats AJS, Van Veldhuisen DJ, Parkhomenko A, Borbola J, Cohen-Solal A, Dumitrascu D, Ferrari R, Lechat P, et al: Randomized trial to determine the effect of nebivolol on mortality and cardiovascular hospital admission in elderly patients with heart failure (SENIORS). Eur Heart J 26: 215-225, 2005.

36. Sturm B, Pacher R, Strametz-Juranek J, Berger R, Frey B and Stanek B: Effect of beta 1 blockade with atenolol on progression of heart failure in patients pretreated with high-dose enalapril. Eur J Heart Fail 2: 407-412, 2000.

37. Uhlir O, Dvorak I, Gregor P, Malek I, Spinarova L, Vojacek J and Van Nueten L: Nebivolol in the treatment of cardiac failure: A double-blind controlled clinical trial. J Card Fail 3: 271-276, 1997.

38. Wisenbaugh T, Katz I, Davis J, Essop R, Skoularigis J, Middlemost S, Röthlisberger C, Skudicky D and Sareli P: Long-term (3-month) effects of a new beta-blocker (nebivolol) on cardiac performance in dilated cardiomyopathy. J Am Coll Cardiol 21: 1094-1100, 1993.

39. Woodley SL, Gilbert EM, Anderson JL, O'Connell JB, Deitchman D, Yanowitz FG, Mealey PC, Volkman K, Renlund DG and Menlove R: Beta-blockade with bucindolol in heart failure caused by ischemic versus idiopathic dilated cardiomyopathy. Circulation 84: 2426-2441, 1991.

40. Bonet S, Agusti A, Arnau JM, Vidal X, Diogène E, Galve E and Laporte JR: Beta-adrenergic blocking agents in heart failure: benefits of vasodilating and non-vasodilating agents according to patients' characteristics: a meta-analysis of clinical trials. Arch Intern Med 160: 621-627, 2000.

41. Hanania NA, Singh S, El-Wali R, Flashner M, Franklin AE, Garner WJ, Dickey BF, Parra S, Ruoss S, Shardonofsky F, et al: The safety and effects of the beta-blocker, nadolol, in mild asthma: an open-label pilot study. Pulm Pharmacol Ther 21: 134-141, 2008

42. Larochelle P, Tobe SW and Lacourcière Y: $\beta$-Blockers in Hypertension: studies and meta-analyses over the years. Can J Cardiol 30 (Suppl 5): S16-S22, 2014.

43. Matowa PR: Beta Blockers Use in Cardiac Failure: Does the Current Prescribing Practice at a Large Urban Hospital in Zimbabwe Exhibit Evidence Based Care and Offer Optimal Therapy for Cardiac Failure Patients? Pharmacology \& Pharmacy 6: 267-279, 2015. 
44. Bangalore S, Makani H, Radford M, Thakur K, Toklu B, Katz SD, DiNicolantonio JJ, Devereaux PJ, Alexander KP, Wetterslev J and Messerli FH: Clinical outcomes with $\beta$-blockers for myocardial infarction: a meta-analysis of randomized trials. Am J Med 127: 939-953, 2014

45. Bavishi C, Chatterjee S, Ather S, Patel D and Messerli FH: Beta-blockers in heart failure with preserved ejection fraction: A meta-analysis. Heart Fail Rev 20: 193-201, 2015.

46. Lu H, Liu X, Guo F, Tan S, Wang G, Liu H, Wang J, He X, Mo Y and Shi B: Impact of beta-blockers on prostate cancer mortality: a meta-analysis of 16,825 patients. Onco Targets Ther 8: 985-990, 2015.

47. Andrews TC, Reimold SC, Berlin JA and Antman EM: Prevention of supraventricular arrhythmias after coronary artery bypass surgery. A meta-analysis of randomized control trials. Circulation 84 (Suppl 5): III236-III244, 1991.
48. Chatterjee S, Biondi-Zoccai G, Abbate A, D'Ascenzo F, Castagno D, Van Tassell B, Mukherjee D and Lichstein E: Benefits of $\beta$ blockers in patients with heart failure and reduced ejection fraction: network meta-analysis. BMJ 346: f55, 2013.

49. Ma ST, Zhao W, Liu B, Jia RY, Zhao CJ and Cui LQ: Association between $\beta 1$ adrenergic receptor gene Arg389Gly polymorphism and risk of heart failure: a meta-analysis. Genet Mol Res 14: 5922-5929, 2015

50. Mostafaie K, Bedenis R and Harrington D: Beta-adrenergic blockers for perioperative cardiac risk reduction in people undergoing vascular surgery. Cochrane Database Syst Rev 1: CD006342, 2015. 